Portland State University

PDXScholar

6-2016

\title{
Graduate-Level Civil Engineering Transportation Course Development - Oregon Tech
}

\author{
Roger Lindgren \\ Oregon Institute of Technology \\ David Thaemert \\ Oregon Institute of Technology \\ Charles Riley \\ Oregon Institute of Technology
}

Follow this and additional works at: https://pdxscholar.library.pdx.edu/trec_reports

Part of the Scholarship of Teaching and Learning Commons, Transportation Commons, and the Transportation Engineering Commons

Let us know how access to this document benefits you.

\section{Recommended Citation \\ Lindgren, Roger, Thaemert, David, and Riley, Charles. NITC-ED-853. Graduate-Level Civil Engineering Transportation Course Development - Oregon Tech. Portland, OR: Transportation Research and Education Center (TREC), 2016. https://doi.org/10.15760/trec.127}

This Report is brought to you for free and open access. It has been accepted for inclusion in TREC Final Reports by an authorized administrator of PDXScholar. Please contact us if we can make this document more accessible: pdxscholar@pdx.edu. 


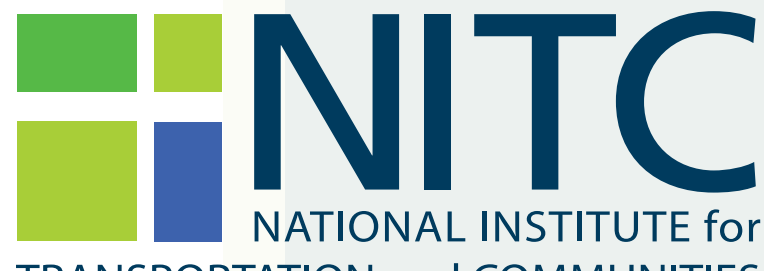

TRANSPORTATION and COMMUNITIES

\section{FINAL REPORT}

Graduate-Level Civil Engineering Transportation Course Development - Oregon Tech

NITC-ED-853 June 2016

NITC is the U.S. Department of Transportation's national university transportation center for livable communities.

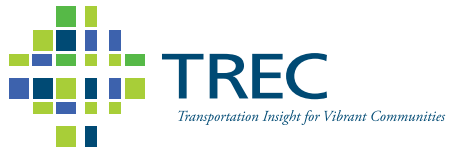




\section{GRADUATE-LEVEL CIVIL ENGINEERING TRANSPORTATION COURSE DEVELOPMENT - OREGON TECH}

\section{Final Report}

NITC-ED-853

by

Dr. Roger Lindgren

Dr. Charles Riley

Dr. David Thaemert

Oregon Institute of Technology

for

National Institute for Transportation and Communities (NITC)

P.O. Box 751

Portland, OR 97207
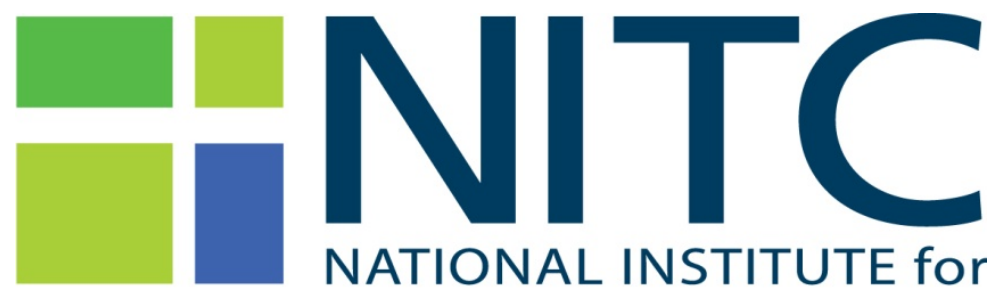

TRANSPORTATION and COMMUNITIES

June 2016 



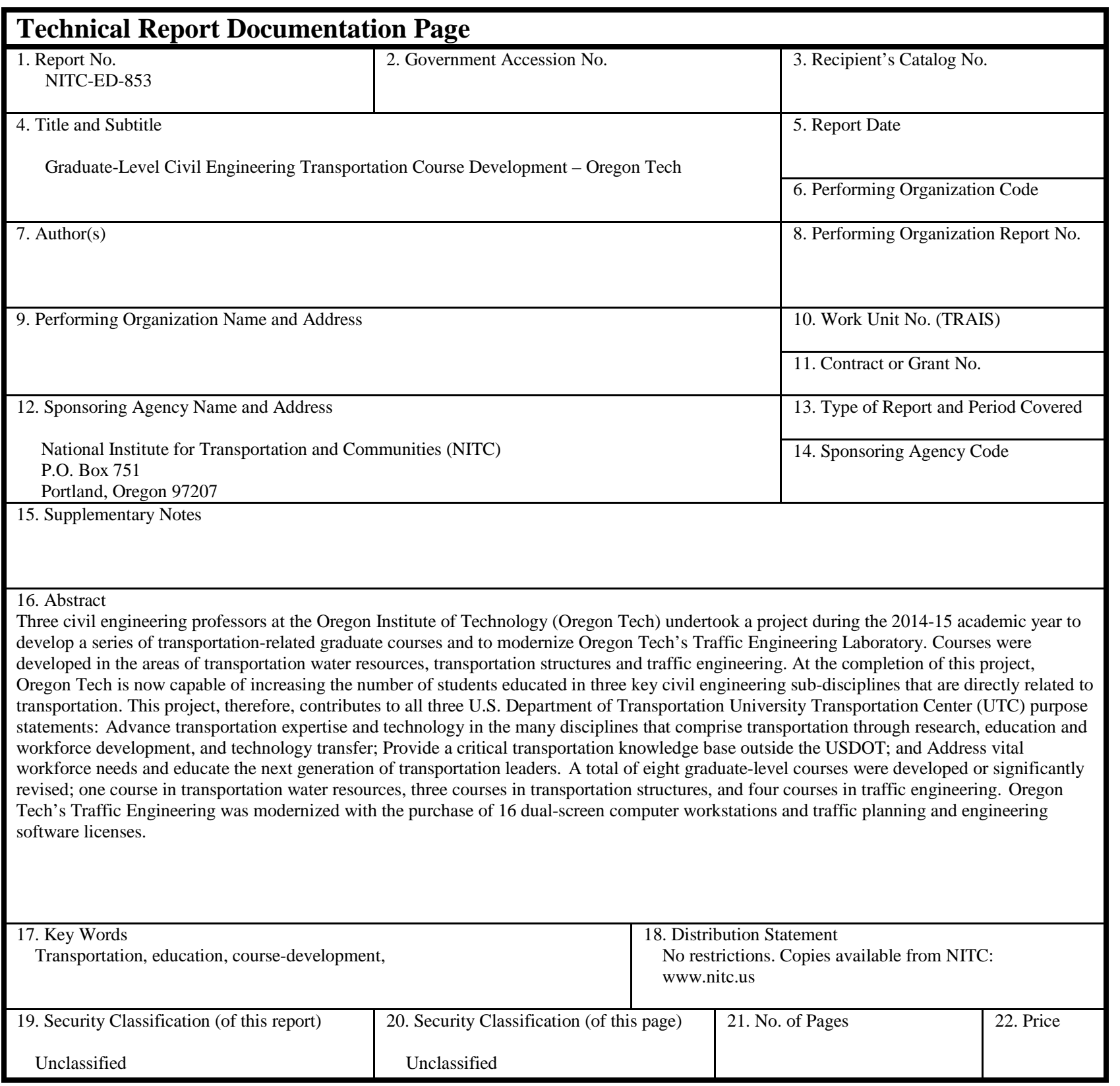





\section{ACKNOWLEDGEMENTS}

This project was funded by the National Institute for Transportation and Communities (NITC) and was supported by the Oregon Tech College of Engineering, Technology and Management.

\section{DISCLAIMER}

The contents of this report reflect the views of the authors, who are solely responsible for the facts and the accuracy of the material and information presented herein. This document is disseminated under the sponsorship of the U.S. Department of Transportation University Transportation Centers Program and the Oregon Institute of Technology in the interest of information exchange. The U.S. Government and the Oregon Institute of Technology assume no liability for the contents or use thereof. The contents do not necessarily reflect the official views of the U.S. Government or the Oregon Institute of Technology. This report does not constitute a standard, specification, or regulation. 



\section{TABLE OF CONTENTS}

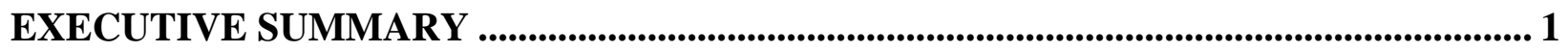

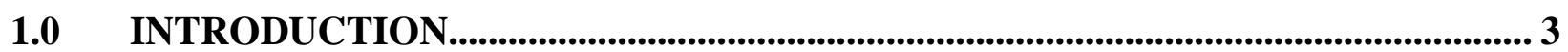

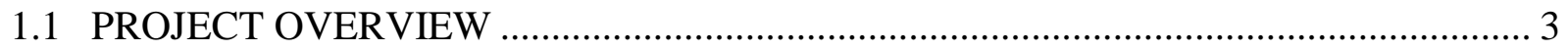

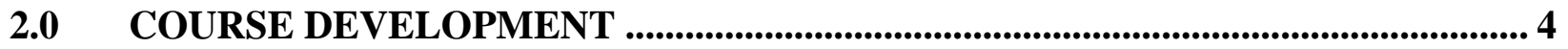

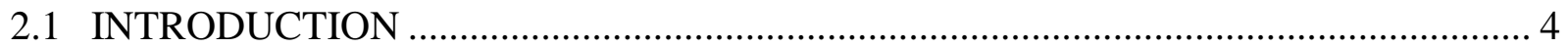

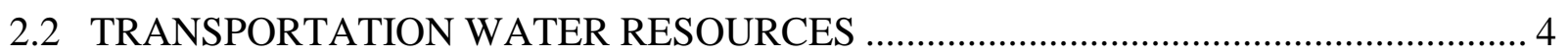

2.2.1 CE476/576 Applied Hydraulic Design ...................................................................... 4

2.2.1.1 Culvert Headwalls ............................................................................................ 5

2.2.1.2 Headwall Trash Rack..................................................................................... 5

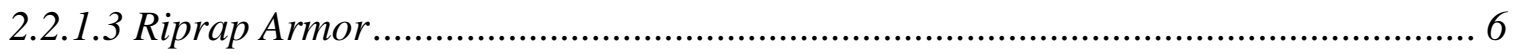

2.2.1.4 Sideslope Riprap ........................................................................................... 7

2.2.1.5 Channel Roughness....................................................................................... 9

2.3 TRANSPORTATION STRUCTURES ………………........................................... 9

2.3.1 CE439/539 Bridge Rating......................................................................... 9

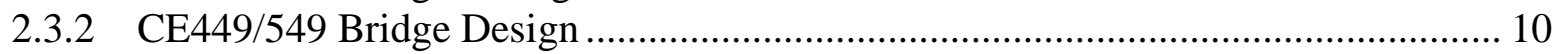

2.3.3 CE450/550 Transportation Structures...................................................................... 11

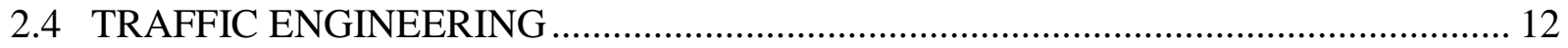

2.4.1 CE551 Geometric Design of Roadways ............................................................... 12

2.4.2 CE554 Advanced Traffic Engineering.................................................................. 12

2.4.3 CE457/557 Transportation and Land Development ............................................ 13

2.4.4 CE468/568 Travel Demand Modeling..................................................................... 14

3.0 TRAFFIC LAB MODERNIZATION ........................................................................... 14

\section{APPENDICES}

APPENDIX A: TRANSPORTATION WATER RESOURCES

APPENDIX B: TRANSPORTATION STRUCTURES

APPENDIX C: TRAFFIC ENGINEERING

APPENDIX D: TRAFFIC LABORATORY MODERNIZATION 


\section{LIST OF FIGURES}

Figure 2.1 Culvert headwall models (flat, 45-degree wingwall) ........................................... 5

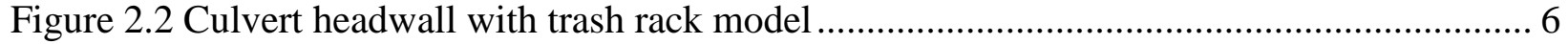

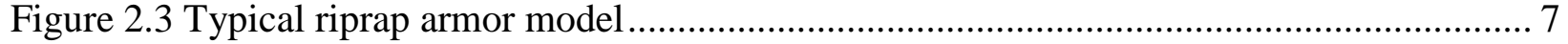

Figure 2.4 Sediment flume streamline transition form ..................................................... 7

Figure 2.5 Typical sideslope riprap model ..................................................................... 8

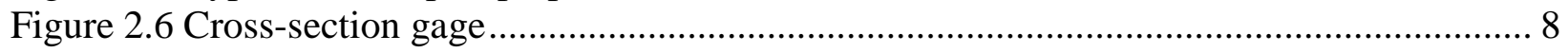

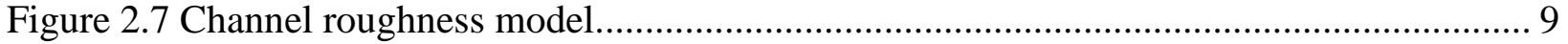




\section{EXECUTIVE SUMMARY}

Three civil engineering professors at the Oregon Institute of Technology (Oregon Tech) undertook a project during the 2014-15 academic year to develop a series of transportationrelated graduate courses and to modernize Oregon Tech’s Traffic Engineering Laboratory.

Courses were developed in the areas of transportation water resources, transportation structures and traffic engineering.

At the completion of this project, Oregon Tech is now capable of increasing the number of students educated in three key civil engineering sub-disciplines that are directly related to transportation. This project, therefore, contributes to all three U.S. Department of Transportation University Transportation Center (UTC) purpose statements:

- Advance transportation expertise and technology in the many disciplines that comprise transportation through research, education and workforce development, and technology transfer;

- Provide a critical transportation knowledge base outside the USDOT; and

- Address vital workforce needs and educate the next generation of transportation leaders.

A total of eight graduate-level courses were developed or significantly revised; one course in transportation water resources, three courses in transportation structures, and four courses in traffic engineering. Oregon Tech's Traffic Engineering was modernized with the purchase of 16 dual-screen computer workstations and traffic planning and engineering software licenses. 



\subsection{INTRODUCTION}

\subsection{PROJECT OVERVIEW}

The Civil Engineering Department at the Oregon Institute of Technology (Oregon Tech) began offering an innovative co-terminal BS/MS degrees program in Fall 2013. Students who enter as freshmen can complete both degree requirements in as few as five academic years by starting graduate coursework in the fourth year while simultaneously completing an undergraduate (senior) project. In the fifth year, students complete remaining undergraduate requirements while focusing on graduate courses and a graduate project. Students choose graduate-level courses from the following sub-discipline areas; geotechnical, structural, transportation and water resources.

Over the past decade, Oregon Tech civil engineering graduates have been actively recruited by transportation agencies and consulting engineering firms specializing in transportation. Thus there has been strong support from alumni and employers for more transportation-related courses at the senior undergraduate and graduate level. Beginning with the 2013-14 academic year the CE Department has been piloting a number of transportation courses, both in the traditional areas (pavements, traffic analysis, geometric design, transport safety, transport planning) and also in multidisciplinary fields such as transportation structures and roadway drainage.

Grant funds provided by the National Institute for Transportation and Communities (NITC) allowed faculty to further develop these transportation-related senior undergraduate and graduate courses to become regular offerings (most offered on a biennial rotation). Undergraduate and graduate students worked with members of the faculty to modernize the primary transportation teaching facility (Oregon Tech's Traffic Laboratory) and develop course work (notes, tutorials, projects, etc.) necessary for the courses to become a permanent part of the CE Department's offerings. Just under half of the NITC funding was devoted to course development, and the remaining funds were used to purchase new computer hardware and software to support the new courses.

While it is impossible to credit any one student's successes to a particular set of courses they have taken, it worth noting that the BS/MS program, in its very early stages, has graduated or will soon graduate (Spring 2016) a total of eight graduate students. Four of these students specialized in transportation and have taken many of the courses described in this report. All four have secured employment upon graduation, three with state departments of transportation in the Pacific Northwest and one with a national traffic engineering firm. While this is purely anecdotal evidence, is does point to the value of education programs undertaken by NITC.

Section 2.0 of this report describes the development of eight new graduate-level, transportationfocused courses in the areas of transportation water resources, transportation structures and traffic engineering. Section 3.0 describes the new computer hardware and software purchased as part of the traffic lab modernization. 


\subsection{COURSE DEVELOPMENT}

\section{$2.1 \quad$ INTRODUCTION}

Oregon Tech's approach to transportation education within the Civil Engineering Department is multidisciplinary in nature. This is, at least in part, due to the relatively small size of the department and the great breadth of courses taught. The department consists of five civil engineering professors; two specializing in structural engineering and one each in the areas of geotechnical, transportation and water resources. There are approximately 120 students enrolled in the department, with approximately 15 actively pursuing graduate (MSCE) degrees. With only one full-time, transportation-focused professor (Dr. Lindgren), the number of transportation-focused graduate courses available to students would be very limited if not for the transportation interests of the water resources faculty member (Dr. Thaemert) and one of the structures professors (Dr. Riley). With NITC funding, these three professors, along with student research assistants, have developed eight new, graduate-level, transportation-focused classes.

The following sections contain summaries of eight graduate-level, transportation-focused civil engineering courses developed or significantly revised in the period 2013-15 and supported by this NITC grant. Section 2.2 describes the first transportation-focused water resources course to be offered at Oregon Tech, CE476/576 Applied Hydraulic Design. Section 2.3 describes three courses, commonly called the "transportation structures series" consisting of CE439/539 Bridge Rating, CE449/559 Bridge Design, and CE450/550 Transportation Structures. Finally, Section 2.4 describes four courses that fall broadly in the category of traffic engineering. They are CE551 Geometric Design of Roadways, CE554 Advanced Traffic Engineering, CE457/557 Transportation and Land Development and CE468/568 Travel Demand Modeling.

It should be noted that three additional graduate-level, transportation-focused classes are taught at Oregon Tech but their development was not directly funded by this grant. They are CE556 Advanced Pavement Design, CE458/558 Transportation Safety, and CE507 Aviation. Where courses contain both $4 \mathrm{xx}$ and $5 \mathrm{xx}$ numbering, they are available for either undergraduate or graduate credit. In this manner, a large number of graduate-level classes in transportation are available to undergraduate students. Undergraduate students may also choose to enroll in CE5xx classes.

\subsection{TRANSPORTATION WATER RESOURCES}

\subsubsection{CE476/576 Applied Hydraulic Design}

Note that the subject course title is revised from the original proposal. In a pilot offering of this transportation-focused hydraulics course, the undergraduate students (CE476) were tasked to prepare a written proposal for a lab-scale hydraulic component related to stormwater conveyance and course content. The intent of this tasking was to determine those topics that were most challenging to understand in the course lecture and lab presentations, and involve students in brainstorming methods that could better illustrate those concepts and associated hydraulic structures. After considering the range of initial student proposals received, five structures were selected for further lab-scale development. 


\subsubsection{Culvert Headwalls}

This structure model included two headwall configurations, with 45-degree wingwalls on either side of a pipe inlet, and flat wall perpendicular to flow. Both of these headwall models are shown in Figure 2.1. Each of these headwall models were intended for use with a pre-existing, corrugated metal pipe (CMP) culvert model (the corrugations are apparent in the figure below).

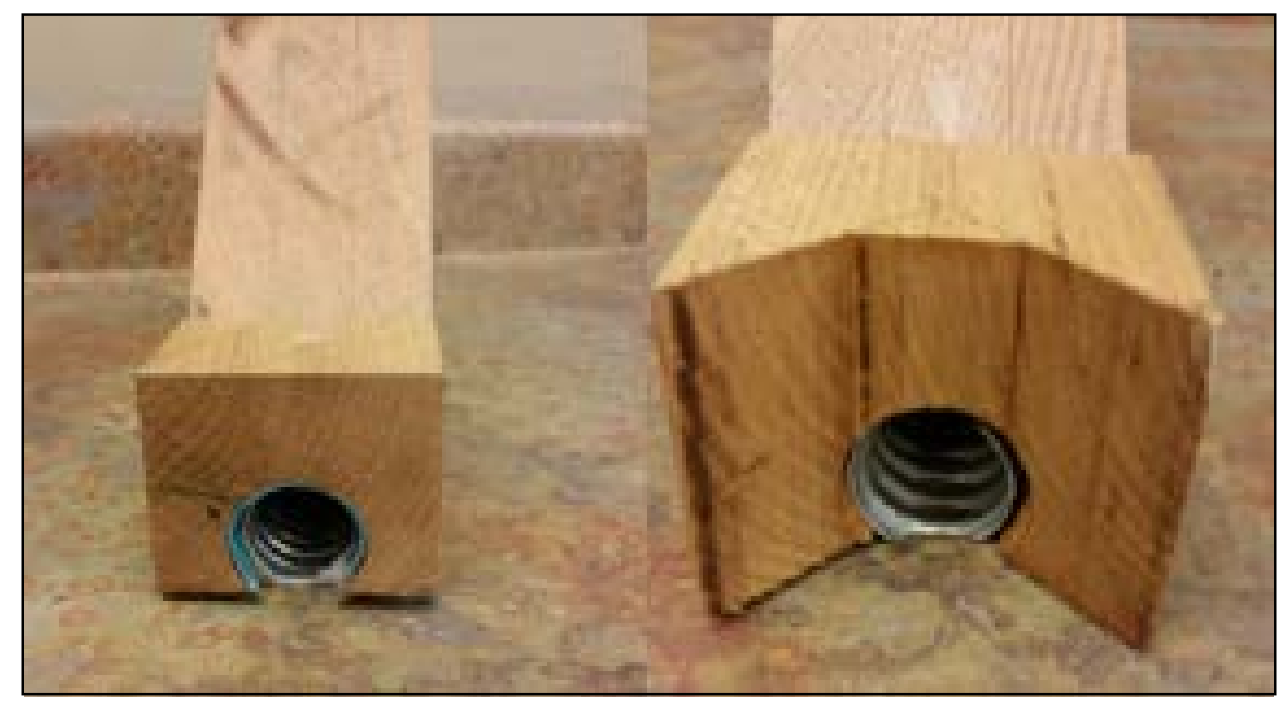

Figure 2.1 Culvert headwall models (flat, 45-degree wingwall)

These models enhance the capability of the pre-existing CMP culvert models by allowing for more variation, and study of the hydraulic effects of such variation, in the pipe inlet conditions. The culvert models, now further enhanced with these headwall models, are used for ad hoc demonstrations of energy loss through culverts and conveyance capacity (including particular demonstration of inlet- versus outlet-controlled conditions) as a function of culvert parameters. In the simplest form, these demonstrations provide students the opportunity to evaluate the hydraulic efficiency of headwalls by comparing differences in upstream flow depth for the same discharge and downstream flow conditions.

An example lab handout that may be used in future course offerings is included in Appendix A of this report.

\subsubsection{Headwall Trash Rack}

This structure model was a variant on the flat headwall model, including screening to allow for interception of introduced debris in the approach channel. This trash rack model is shown in Figure 2.2. As before, this headwall model was intended for use with a pre-existing CMP culvert model. 


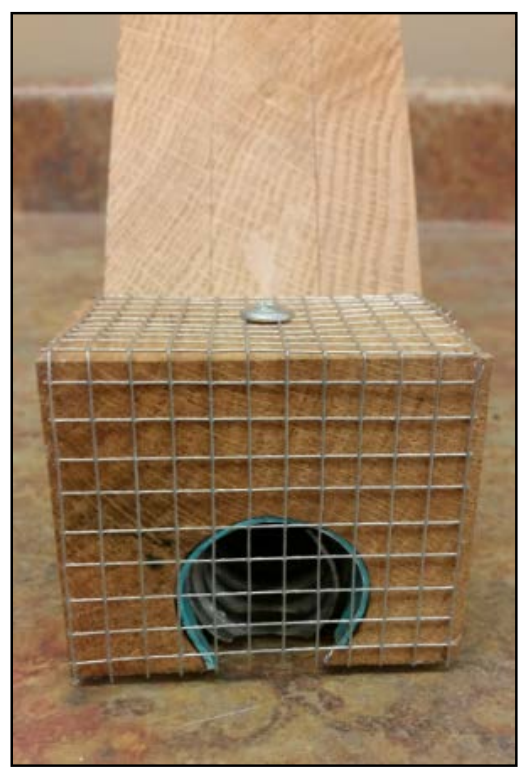

Figure 2.2 Culvert headwall with trash rack model

This model also enhances the capability of the pre-existing CMP culvert models by allowing for more variation, and study of the hydraulic effects of such variation, in the pipe inlet conditions. This trash rack model will allow classroom-related study of the effects of debris in open channels. As a reliable debris interception and filtering system - to prevent clogging and potential failure of the 5-m flume's hydraulics benchhas not yet been reliably developed, this model has not yet been tested with any debris application, rather purely hydraulic conditions.

\subsubsection{Riprap Armor}

This modeling effort implemented a previously constructed, smooth culvert model prepared for the sediment demonstration channel, a small flume with sediment recirculation capabilities. Various sizes of uniformly graded sediments, taken from the pavement laboratory supplies, were placed downstream of the culvert model. A typical experimental setup of this model is shown in Figure 2.3. 


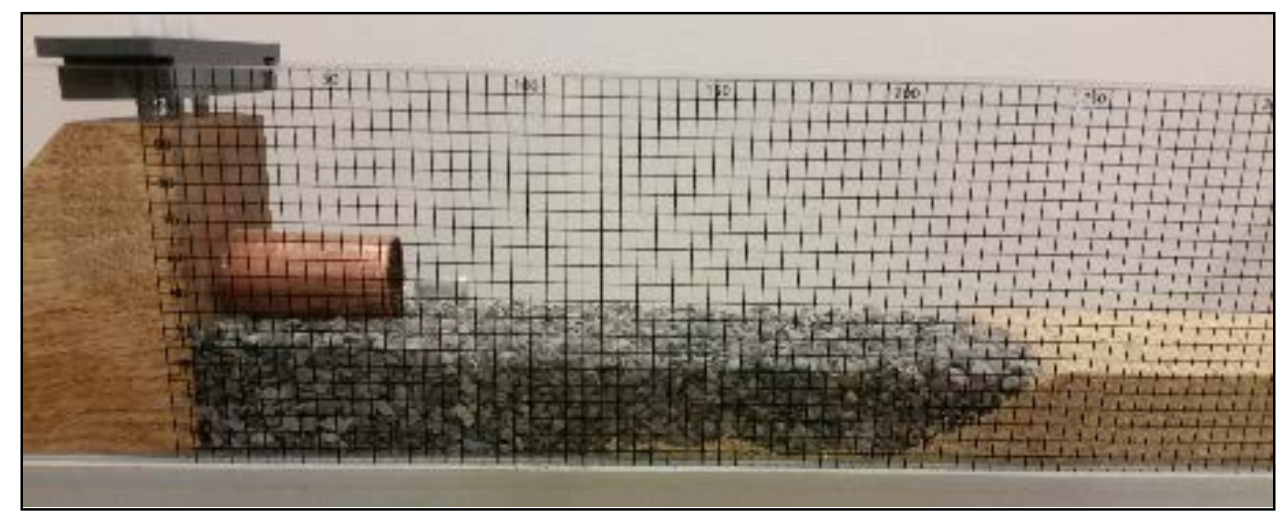

Figure 2.3 Typical riprap armor model

Several hydraulic runs were completed for a range of aggregate sizes, channel slopes, and discharge values. These were completed to determine at which grain size a culvert scour hole would readily develop for classroom demonstration purposes. Future ad hoc laboratory assignments will be made to confirm this initial work.

\subsubsection{Sideslope Riprap}

This modeling effort was intended to reflect riprap performance in a barrow ditch or similar open channel, and was again prepared in the sediment demonstration channel. Various sizes of uniformly graded sediments, taken from the pavement laboratory supplies, were placed downstream of a streamline transition form, as shown in Figure 2.4.

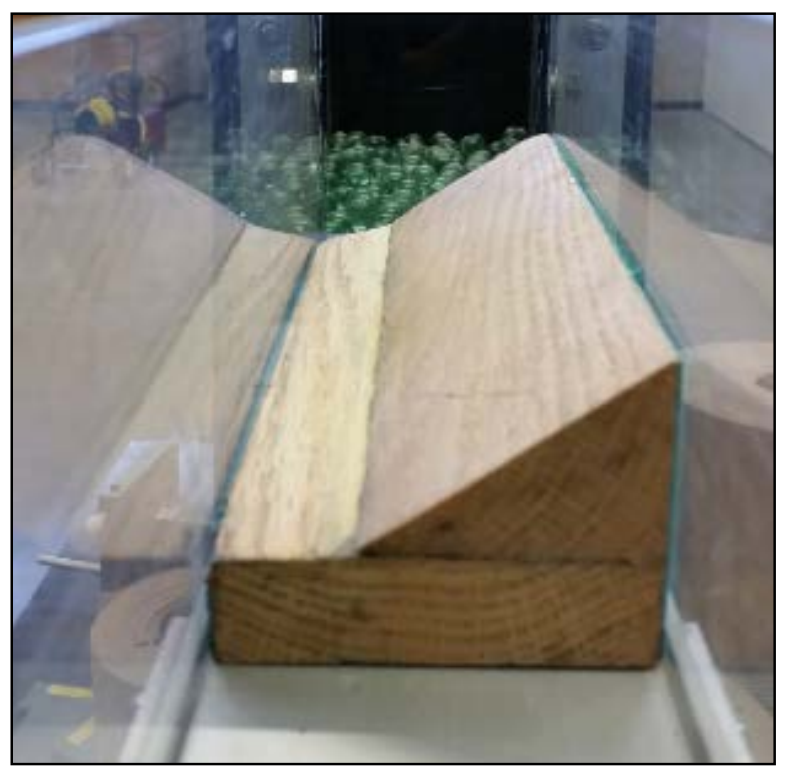

Figure 2.4 Sediment flume streamline transition form 
After the transition piece at the head of the flume, a range of uniformly graded aggregate sizes were used to model half of a trapezoidal channel, such as a barrow ditch. Figure 2.5 shows a typical setup of the sideslope riprap model.

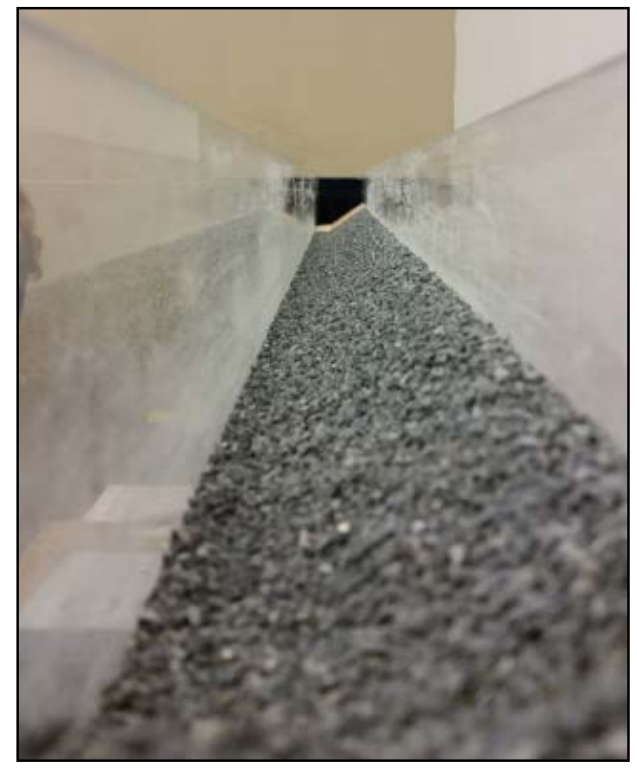

Figure 2.5 Typical sideslope riprap model

Several hydraulic runs were completed for a range of aggregate sizes, channel slopes, and discharge values. These were completed to determine at which grain size observable slope riprap failure might occur for classroom demonstration purposes. A cross-section gage was crafted to enable measurement of aggregate displacement before and after a particular flow event. The cross-section gage is shown in Figure 2.6.

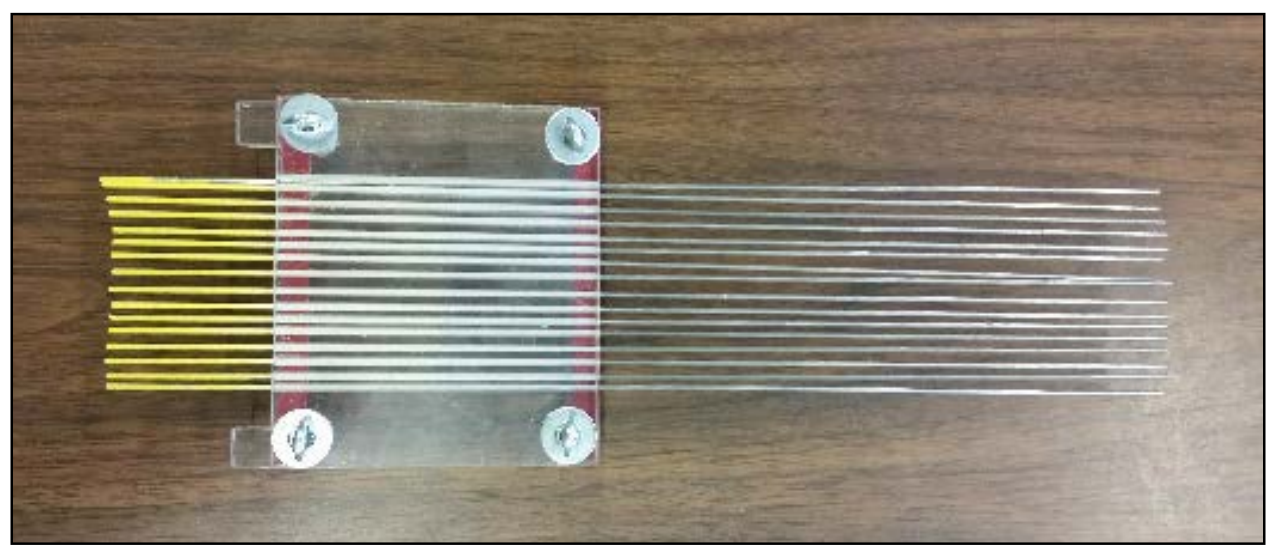

Figure 2.6 Cross-section gage

Future ad hoc laboratory assignments will be made to confirm this initial work. 


\subsubsection{Channel Roughness}

This demonstration model was developed for the 5 -m flume. The components of this model, not yet installed in the flume, are shown in Figure 2.7.

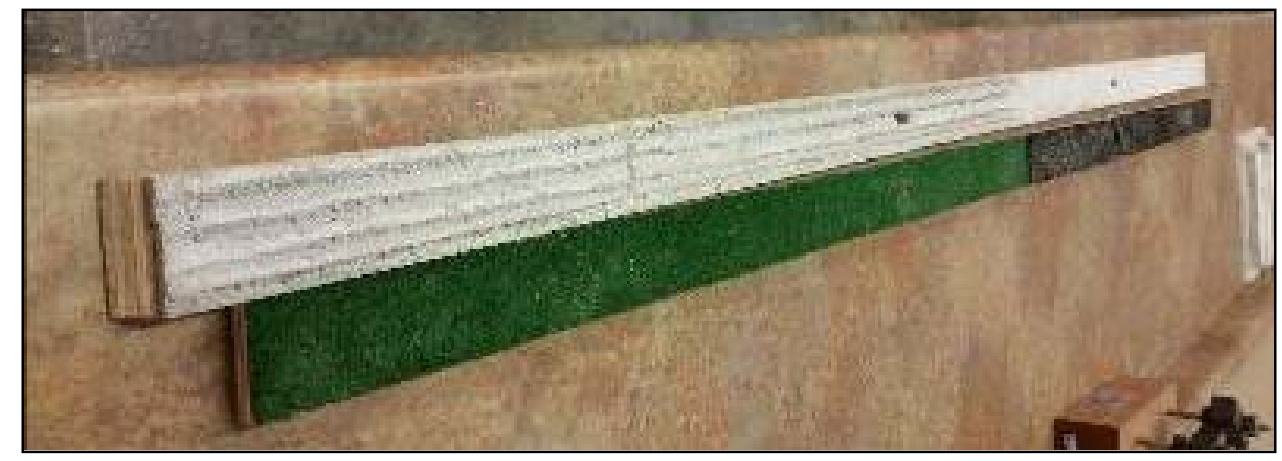

Figure 2.7 Channel roughness model

This model demonstrates the effects of surface roughness on hydraulic depth and velocity using four different channel lining materials typically found in transportation-related open channels. These materials include, from upstream to downstream, turf (using a synthetic turf material in this application), asphaltic cement concrete, and tined and smooth portland cement concrete. Future ad hoc laboratory assignments will be made to confirm this initial work.

\subsection{TRANSPORTATION STRUCTURES}

The transportation structures course sequence addresses transportation structures in order of importance. It aligns with cognitive levels of development starting with knowledge, comprehension and analysis (bridge rating), and moves to analysis and synthesis (bridge design) and ultimately to evaluation (structural design philosophy and reliability via ancillary structures like culverts and light poles).

\subsubsection{CE439/539 Bridge Rating}

Bridges are the most expensive element in a transportation network and the focus in bridge asset management is currently on cost-effective evaluation, repair and retrofit. Evaluating existing bridges provides an appropriate entry point for students interested in bridges, gives them a valuable skill that can be applied immediately, and provides a basis for the more challenging task of bridge design that comes later. Bridges have a common form and relatively regular proportions, but they are unique to their location. In Bridge Rating, students examine a variety of types of existing bridges through field evaluation and National Bridge Inventory review, and evaluate them using Oregon Department of Transportation (ODOT) procedures and American Association of State Highway and Transportation Officials (AASHTO) design and rating 
specifications. Through this process, students grow comfortable with bridge types, failure modes, design and rating specifications, rating processes, and common bridge condition parlance like condition and sufficiency rating, which drives so much of the funding and prioritization of bridge repair and replacement.

This course was developed originally with a textbook that addressed both bridge design and bridge rating, but it was clear that a textbook devoted to bridge rating was necessary. Fortunately, Lubin Gao, Federal Highway Administration (FHWA) load rating engineer, published such a text in 2013 as the first iteration of this course was being offered. The text was referenced in that year, was appreciated by students and instructor alike, and used as the required text in fall 2015 during the second iteration.

The basis of this course is area highway bridges, which serve as case studies. Their rating results are available and design drawings obtained from ODOT. Students examine these bridges in the context of the National Bridge Inventory, and attempt to analyze and rate these bridges using hand methods, spreadsheets developed during multiple laboratories, and BRASS, a software package developed at the Wyoming DOT (WYDOT) that is used by ODOT. The course professor (Dr. Riley) was employed at WYDOT and has extensive experience with BRASS.

The course was developed for a 10 -week term with two 50-minute lecture periods and one threehour field or computational laboratory session per week. Course materials for the most recent offering of this course can be found in Appendix B, and include a syllabus, student study guide, assignments, laboratory assignments, computation spreadsheets, a BRASS input tutorial, and BRASS input and output files for class and laboratory exercises.

\subsubsection{CE449/549 Bridge Design}

While the Bridge Design course was originally intended to require a prerequisite of Bridge Rating, the nature of the program at Oregon Tech means that our elective courses should stand alone to serve the greatest population of students. Therefore, this course was taught in a fairly straightforward manner with topics treated as offered by Barker and Puckett in their Design of Highway Bridges: An LRFD Approach, $3^{\text {rd }}$ Ed. This text has been substantially expanded from its earlier editions to serve as a fairly complete highway bridge design reference. While it contains much more than can be covered in a 10-week course, its approach to providing content matches the intended structure of the CE449/559 course.

Bridge types and the state of America's bridges are introduced, as are historical bridge failures and their impact on current practice and bridge aesthetics, so students have the sense that bridges are not simply engineered structures, but that they have an impact on nearly everyone who uses them. An aesthetic failure can be devastating to a community in ways different but sometimes more lasting than a structural failure. Bridge design philosophy is taught next with type, size and location studies providing the basis for a midterm group project that emphasizes the practical challenges of bridge design and the creativity necessary for successful solutions. Students use diverse resources including AASHTO, ODOT and material supplier information. Loads and structural analysis are covered with a combination of hand calculations, spreadsheets and 
commercial software. An early laboratory on structural dynamics and structural health monitoring (part of another NITC-funded project) provides the basis for an example of seismic analysis of bridges. Finally, in the last half of the course, concrete and steel bridges are treated. Concrete in bridges is examined via deck analysis and prestressed girder design. A composite steel girder design serves as a final project that captures bridge design methodology with bridge and girder proportioning. Students begin with loads; work through dead and live load distribution, girder-line analysis, and composite girder design using AASHTO specifications; and ultimately iterate to optimize their girder spacing and proportions for a single limit state and action.

The course was developed for a 10-week term with three 50-minute lecture periods and one three-hour field or computational laboratory session per week. Course materials for the most recent offering of this course can be found in Appendix B, and include a syllabus, student study guide, assignments, laboratory assignments, computation spreadsheets, and PowerPoint presentations, which are not exhaustive as this is not the primary method of delivery. An excellent survey was recently conducted regarding bridge design topics and presented at NASCC: The Steel Conference. The intent is to modify the CE449/559 course based on some of the suggestions found here: http://bridgeeducation.weebly.com/survey-results.html.

\subsubsection{CE450/550 Transportation Structures}

The final course in the sequence uses ancillary transportation structures like culverts, high-mast light towers and sign structures as case studies through which we explore safety and reliability of structural elements in the transportation system as well as advanced topics like nonlinear structural analysis, accumulated damage and fatigue, Monte Carlo simulation and probabilistic design of structures.

This course uses no required text, but relies on ODOT standard drawings and design recommendations, instructor notes and journal papers. The course connects to the two bridge courses via culverts as a first topic. Buried structures require a different application of loads and are often analyzed using different methods than bridges. Development of spreadsheet-based analysis and design tools has proven to be an engaging and powerful method for teaching this topic. Students appreciate the detailed treatment of the material and the result is a tool they can take with them and use in the future. Similarly, high-mast light towers and sign structures are wind-sensitive structures that provide the opportunity to develop bluff-body aerodynamics principles and discuss combined loadings. The nonlinear analysis methods for these types of structures are different than most methods students have encountered previously. The rigorous development of a spreadsheet tool to conduct nonlinear analysis and extend a discrete analysis to a probabilistic one via Monte Carlo simulation provides for a valuable treatment of advanced topics that are covered in multiple graduate-level courses at other institutions. The value in this treatment for an institution like Oregon Tech is that the structures are all real structures rather than simplified problems, the advanced topics are taught via application rather than theory, and as a unifying characteristic the case studies support a safe and reliable transportation network. This point is emphasized throughout the course to provide the basis for studying such challenging topics. 
The course was developed for a 10-week term with two 50-minute lecture periods and one threehour field or computational laboratory session per week. Course materials for the most recent offering of this course can be found in Appendix B, and include a syllabus, student study guide, and computation spreadsheets that along with the study guide demonstrate the depth of calculation and exploration of these structures.

\subsection{TRAFFIC ENGINEERING}

The four courses described in this section comprise the graduate-level traffic engineering offerings at Oregon Tech. Each course has been designed to be taken after students have completed junior-level, pre-requisite work in CE351 Introduction to Transportation Engineering and CE354 Traffic Engineering. Many students with an interest in transportation, prior to enrolling in graduate-level classes, also pursue a transportation focus in the senior-level project course series consisting of CE401 Civil Engineering Project I and CE402 Civil Engineering Project II.

\subsubsection{CE551 Geometric Design of Roadways}

The geometric design course at Oregon Tech was taught for the first time in Fall 2013 and is currently being taught for a second time (Spring 2016). The primary objectives of this class are to:

- Utilize AASHTO and other guidelines to design roadway geometry

- Understand the complexity and human-vehicle-roadway interactions

- Integrate safety, local culture, livability and sustainability into roadway designs

- Describe the relationship between transport design professionals and entities such as AASHTO and Institute of Transportation Engineers (ITE)

The primary reference is AASHTO's 2011 A Policy on Geometric Design of Highway and Streets, the so-called "Green Book." Geometric design is defined by AASHTO as the positioning of the physical elements of the roadway according to standards and constraints. While the basic objectives in geometric design are to optimize efficiency and safety while minimizing cost and environmental damage, the design of roads and streets also affect a community's "livability;" the fostering of broader community goals, including providing access to employment, schools, businesses and residences; accommodating a range of travel modes such as walking, bicycling, transit and automobiles; and minimizing fuel use. To this end, at critical points in this class, students are encouraged to look beyond the "Green Book" and look at practical designs which promote livability.

A course syllabus, course notes and assignments can be found in Appendix C of this report.

\subsubsection{CE554 Advanced Traffic Engineering}

This course was developed to follow up on a required, junior-level course, CE354 Traffic Engineering. The motivation for the course was the National Transportation Curriculum 
Project's (NTCP) https://nationaltransportationcurriculumproject.wordpress.com/ 2009 meeting of transportation educators held in Portland, OR. This meeting, sponsored by the National Science Foundation (NSF), aimed to develop a new set of curricular materials for introductory courses in transportation engineering. Oregon Tech faculty in attendance at the 2009 meeting began using signalized intersection materials created by University of Idaho professor, Dr. Michael Kyte, which were eventually compiled and published as Operation, Analysis, and Design of Signalized Intersections and co-authored by Dr. Kyte and Maria Tribelhorn. This workbook was used as a required text in the inaugural offering of CE354 Traffic Engineering in Spring 2014.

Based on the success of using the Kyte workbook in CE354, it was determined that Kyte's more comprehensive text Traffic Signal Systems Operations and Design, co-authored by Dr. Tom Urbanik, would be trialed for use in CE554 Advanced Traffic Engineering. This was offered for the first time in Winter 2015 and was taught in the newly refurbished Oregon Tech Traffic Engineering Lab. Since the Traffic Lab now contains microscopic traffic simulation software (Vissim), the Kyte/Urbanik text material can be fully implemented and tested by students using simulated traffic intersections. After introductory material from the text is covered in the lecture portion of the class, students embark on a six-week laboratory project wherein they collect data from a Klamath Falls area intersection and create a fully functioning microscopic simulation model of the intersection. Student research assistants were employed under the grant to develop a series of instructional modules for use of the VISSIM software. These modules, along with a course syllabus and course notes, can be found in Appendix C of this report.

\subsubsection{CE457/557 Transportation and Land Development}

The transportation and land development course (CE457/557) was taught for the first time in Fall 2014, although elements of the course had been trialed under a different course prefix. This previous experience determined that students learned more in a project-based learning environment with a focus on practical implementation instead of a strictly theoretical coverage of the course material. These pedagogical techniques are in line with Oregon Tech's overall approach to engineering education. Therefore, for the 2014 offering it was determined that a moderately large project in a nearby community would be chosen as the focus of the course, and that the key student deliverable (a traffic impact assessment) would follow the specifications of the practice-oriented ITE publication titled Recommended Practice Transportation Impact Analyses for Site Development.

Since there is limited development taking place in Klamath Falls, the 22-acre Goodpasture Island Mixed-Use Planned Unit development in Eugene, OR, was used as the case study for this course.

Additionally, after consulting with Oregon Tech’s Civil Engineering Industrial Advisory Committee, it was determined that this course would be the appropriate venue to introduce pedestrian and bicycle design elements to students until a stand-alone course devoted to bike/ped design is developed. Thus, approximately one quarter of the 10 -week term was devoted to principles of design for bicycle and pedestrian facilities. The primary references for this portion 
of the class were obtained from the Pedestrian and Bicycle Information Center at the University of North Carolina - Chapel Hill.

A course syllabus, course notes and assignments can be found in Appendix C of this report.

\subsubsection{CE468/568 Travel Demand Modeling}

CE468/568 Travel Demand Modeling was taught for the first time in Spring 2015. The initial plan for this course was to present the underlying theory in the first half of the term, and proceed to implement this knowledge using PTV Visum software in the second half of the course. After reviewing relevant texts and discussing this idea with Dr. Kelly Clifton of Portland State University, it was determined that a more reasonable approach would be to devote all 10 weeks of this course to presentation of the underlying theory using simpler computer models, such as spreadsheets when applicable. This leaves the implementation of Visum software to a second travel demand modeling course which has yet to be developed.

For the inaugural offering of this course, the text Modeling Transport by J. Ortuzar and L. Willumsen was chosen. The primary course topics were:

- The Context of Travel Demand Modeling

- Transportation Data and Preliminary Analysis

- Trip Generation Modeling

- Trip Distribution Modeling

- Modal Split and Direct Demand Models

- Discrete Choice Models

- Traffic Assignment Models

A complete course syllabus, course notes and assignments can be found in Appendix $\mathrm{C}$ of this report.

\subsection{TRAFFIC LAB MODERNIZATION}

The Traffic Engineering Laboratory is a 1,200-square-foot dedicated facility in Cornett Hall on Oregon Tech's Klamath Falls campus. The lab consists of a student work area, a technical library and 16 computer workstations (including an instructor station). The computers serve as the computation backbone for nearly every transportation-related course, and contain software for pavement design, geometric design, travel demand modeling, bridge design/rating, traffic analysis and microscopic traffic modeling. The workstations in use prior to this 2014-15 NITC grant were purchased in 2007 with funding support from the Oregon Transportation Research and Education Consortium (OTREC) and Oregon Tech's College of Engineering, Technology, and Management. These 2007 era workstations (Del Optiplex 745, 2GB RAM) were at the end 
of their functional life and, due to a lack of sufficient RAM memory and graphics processing capability, could no longer efficiently run modern traffic analysis software such as the PTV Vision Suite used in several of Dr. Lindgren's courses. The Vision Suite software consists of Vistro, a traffic impact analysis package used in CE457/557 Transportation and Land Development; Vissim, a microscopic traffic simulation modeling package used in CE354 Traffic Engineering and again in CE554 Advanced Traffic Engineering, and CE551 Geometric Design of Roadways; as well as Visum, a traffic demand modeling package. Bridge rating in CE439/539 Bridge Rating employs BRASS (Bridge Rating \& Analysis of Structural Systems) software produced by the Wyoming Department of Transportation (also used by ODOT). Students in CE449/559 Bridge Design and CE450/550 Transportation Structures use BRASS as well as Microsoft Excel-based Monte Carlo analysis of transportation structures which are computationally intensive and also benefited from newer, faster workstations.

The funds provided by NITC in this grant allowed for the purchase of 16 new computer workstations (Dell Optiplex 9020, 8GB RAM) as well as an upgraded license to operate PTV Vision Traffic Suite Software.

PTV Vistro was developed specifically for traffic analysis, assists transportation planners and traffic engineers with their traffic impact analysis projects, and is perfectly suited to support the objectives of Oregon Tech's CE457/557 Transportation and Land Development. The software offers a selection of industry-standard analysis methodologies, such as the Highway Capacity Manual (HCM) 2010 and HCM 2000 metrics including volume-to-capacity, level of service (LOS) and delays.

PTV Vissim allows the user to simulate real traffic patterns on a computer screen. These include motorized private transport, heavy goods (truck) transport, rail and road-related public transport, as well as pedestrians and cyclists. Vissim displays all road users and their interactions in one model, making it an ideal teaching platform for both Oregon Tech's introductory and advanced traffic engineering courses. The software offers flexibility in several respects: the concept of links and connectors allows users to model geometries with any level of complexity.

PTV Visum is one of the world's leading software packages for traffic analyses, forecasts and GIS-based data management. It models all road users and their interactions. Transportation students can use PTV Visum to model transport networks and travel demand, to analyze expected traffic flows, to plan public transport services, and to develop advanced transport strategies and solutions.

This grant also supported the expansion of the Traffic Lab’s technical library, adding AASHTO's Manual for Bridge Element Inspection, A Policy on Geometric Design of Highways and Streets and Highway Safety Manual.

Specifications for both the Dell computer workstations and the PTV software purchased under this grant can be found in Appendix D of this report. 
Transportation Research and Education Center

Portland State University

1900 S.W. Fourth Ave., Suite 175

Portland, OR 97201 